\title{
Structural Organisation of Research Article Titles: A Comparative Study of Titles of Business, Gynaecology and Law
}

\author{
Kingsley Richard Appiah ${ }^{1}$, Christopher Ankomah ${ }^{1 *}$, Harrison Yaw Osei ${ }^{1}$, Timothy Hattoh-Ahiaduvor ${ }^{2}$ \\ ${ }^{\prime}$ Department of English, University of Cape Coast, Ghana \\ ${ }^{2}$ Department of English, Jasikan College of Education, Ghana \\ Corresponding Author: Christopher Ankomah, E-mail: krisanko31@gmail.com
}

\section{ARTICLE INFO}

Article history

Received: February 05, 2019

Accepted: May 14, 2019

Published: June 30, 2019

Volume: 10 Issue: 3

Advance access: May 2019

Conflicts of interest: None

Funding: None

\section{Key words:}

Cross-disciplinary,

Ra Titles,

Style,

Syntactic Structures,

Text Length

\begin{abstract}
Since titles are gateways to the heart of research articles (RAs), their organisational structure should be regarded very crucial in appealing to the potential reader. This study aimed to investigate how titles of RAs are presented in three disciplines (Gynaecology/Obstetrics, Business, and Law). After a thorough study of 574 titles, the study revealed that Business titles were averagely longer than those in the other two disciplines. In terms of title style, it was revealed that the Single Unit Title was extensively used in Gynaecology/Obstetrics and Law, while the Compound Unit Title dominated the Business titles. Syntactically, Noun Phrases extremely dominated the Single Unit Titles across the three domains. Detailed examination of the NP modifications showed that nominal titles which were both Pre and Post-modified were highly frequent in all the disciplines, which contrasts what is in the literature. The study also identified the Prepositional Phrase as the commonest structure used in post-modifying the nominal structures than using nonfinite clauses in all the disciplines. Again, colon was the most predominant punctuation mark used in partitioning the Compound Unit Titles across the three disciplines, with Law recording the highest followed by Gynaecology/Obstetrics and Business. Lastly, the data exhibited high frequency of Domain-Specific words in the titles more than Research-Based words across the disciplines. This study provides useful information on the nature of effective RA titles to novice writers and advanced authors. It also informs the teaching of academic writing skills.
\end{abstract}

\section{INTRODUCTION}

The role research articles play is enormous in academia. A peer-reviewed journal often provides a common platform and exceptional environment for readers and researchers to interact, in order to improve knowledge search. This knowledge exploration is often carried through the title of the research article (RA). The title serves as the lens through which the potential readers see the content of a manuscript or the article, which makes title an important part of a paper (Bavdakar, 2016; Fox \& Burns, 2015; Imbelloni, 2012). This is an indication that readers' easy contact with a body of knowledge is generally conveyed through the title. The title is a leading path to what readers are looking for in the literature. In the view of Grant (2013), a well written title should facilitate an easy search on a topic area by providing, in clear terms, what the reader expects. This means that titles should clearly articulate their contents to potential readers because they are the first impression readers get about the article. In this case, a research article must distinguish its distinctive content through the title (Cheng et al., 2012). Consequently, authors carefully compose titles with the intention to attract large readership and academic attention (Cheng et al., 2012; Hudson, 2016).
Over the years, journals have showcased these titles through the tables of content. Moss (2003) indicates that these titles serve as signpost to attract readers to patronise papers and, as a result of that, titles might be the only segment of the paper that will be read. Almost all journals require authors submitting manuscripts for publication to write concise and informative titles. One major problem authors face is how to construct effective titles to meet this requirement. In view of this, titles have been studied from varied perspectives, in terms of title length (e.g., Afful, 2017; Hudson, 2016), the effects of title form and length on the rate of citation (e.g., Fox \& Burns, 2015; Jamali \& Nikzad, 2011; Whissell, 2013), syntactic organisation (e.g., Afful, 2017; Cheng et al., 2012), diachronic lens (e.g., Rahman \& Hussein, 2016) or informativity/semantic content (e.g., Afful, 2017; Rahman $\&$ Hussein, 2016). There are other studies which have focused on a single discipline (e.g., Cheng et al., 2012; Wang \& Bai, 2007; Whissell, 1999) or multidiscipline (e.g., Fortanet et al., 1997; Haggan, 2004; Nagano, 2015). Although literature shows that titles have been studied from macro or microstructure levels in individual disciplines (e.g., Cheng et al., 2012) and cross-disciplinary perspectives (e.g., Fortanet et al., 1997; Haggan, 2004), detailed investigation of RA

Published by Australian International Academic Centre PTY.LTD.

Copyright (c) the author(s). This is an open access article under CC BY license (https://creativecommons.org/licenses/by/4.0/) http://dx.doi.org/10.7575/aiac.alls.v.10n.3p.145 
title syntactic structures appears inadequate. Besides, journals continue to remain vague in their definition for concise and informative titles. Consequently, using three disciplines for illustration, the current study attempts to explore the syntactic structures of RA titles from the disciplines of science, business and law. It is through a comparative study that the organisational parts of titles can be compared relatively to establish, for instance, the shortness or lengthiness of titles.

Therefore, this study aimed to investigate both the macro-structure and micro-structure of RA titles cross disciplinarily, in order to reveal how effective titles of research articles (RAs) are presented in an appealing manner to their respective readers. In other words, addressing the gap will contribute significantly to effective construction of RA titles by novice and experienced authors. It will also guide the teaching of academic writing skills. This study is guided by two research questions: (1) What are the syntactic structures of titles of gynaecology/obstetrics, business, and law? and (2) Which lexical choices are commonly explored in the titles of gynaecology/obstetrics, business, and law?

\section{LITERATURE REVIEW}

Certainly, there is a growing body of knowledge in the literature that suggests that there are different perspectives through which different disciplines present their research article titles. The next few pages present literature on the status of title length, title categorisation and lexical choices.

\section{Title Length}

The text length of a particular genre plays a significant role of identifying the text as a unique text (Kang \& Yu, 2011). The appropriate length of a title is not emphatic and remains debatable (Bavdakar, 2016). For instance, in Day's (1998, p. 5) view, a good title should be seen as the one with "the fewest possible words that adequately describe the contents of the paper." Here, 'fewest possible words' are unexplained and relative. It means that what constitutes the average length of research article titles is generally uncertain. This is an indication that there is silence on how long a title of a research article should be. However, the findings of some empirical studies appear to suggest that the number of an average title length can be pegged around 6.4 (Afful \& Mwinlaaru, 2010) and 13.8 (Haggan, 2004) words per title across various disciplines. For instance, Whissell (1999) reported that the average title length of RAs was 12 words long in psychology. In medical RA titles, Wang and Bai (2007) found 10.9 words to be the average length of titles.

It is also generally claimed that science titles are longer than humanity titles (Busch-Lauer, 2000; Haggan, 2004; Fortanet et al., 1997; Nagano, 2015). For instance, in Busch-Lauer's (2000) study of 150 German and English titles of RAs and conference paper titles, the average title length was found to be longer in medicine (9.9 words) than that of linguistics (8.4 words). Again, Haggan (2004) demonstrated that the average title length of science RA titles were longer than those of literature and linguistics. However, this claim was found to be directly opposite of what Anthony (2001) found. In studying RAs in computer science, applied linguistics, business and economics, and chemistry, Fortanet et al. $(1997,1998)$ reported that the shortest title length was found in applied linguistics while chemistry titles were found to be the longest in all the disciplines studied.

\section{Classifications of Titles}

Since the study of titles of research articles or conference papers became common in research, different scholars have categorised titles into varied groups. Some have classified them based on the segments in which the titles are presented. In such situations, titles have been placed under two main categories: single unit and multiple unit (e.g., Afful, 2017; Afful \& Mwinlaaru, 2010; Nagano, 2015). There are others who classify titles into grammatical functions/structures in which they are presented, for example, declarative titles, descriptive/informative titles and interrogative titles (e.g., Bavdakar, 2016; Jamali \& Nikzad, 2011). To Bavdakar, the descriptive title is the most preferred one because it creates suspense. The declarative title discloses the main findings; the interrogative title is a restatement of the research question; and the descriptive title indicates the details of the study but does not disclose the findings. However, Day (1998) guards against writing titles in sentences, especially in science, because titles are supposed to serve as labels of papers and not to inform the readers about the outcomes.

According to Bavdakar (2016), titles can also be grouped based on the point of view of a construct leading to nominal, compound and full-sentence titles. Other scholars combine the structural units and the kind of functions or grammatical structures in which the titles are arranged. For instance, in examining the syntactic structure and function of research article titles in applied linguistics, Cheng et al. (2012) identified five types of titles: compound, nominal, full-sentence, $\mathrm{V}$-ing phrase and the prepositional phrase. The compound titles were identified as the most frequent titles employed, which constituted more than half of the occurrences followed by the nominal titles. The prepositional phrase was the most widely used post-modifier of the nominal heads. The current study adopted the binary approach, where titles are classified according to the components in which they are presented.

\section{Lexicons of Titles}

In writing research article titles, there have been different suggestions relating to the choice of words. For instance, there are certain expressions that should be avoided in writing an effective title (Bavdakar, 2016; Day, 1998; Gustavii, 2008). These scholars contend that titles should include as many key words as possible in order for the title to aid electronic indexing and search. They argue that writers should, therefore, avoid research-based words/ phrases such as "investigation of", "study of" or "observation on" because they create redundancy to make titles longer, especially in science. Day (1998) adds that, apart from these research-based words, articles ( $a$, an and the) must be avoided, especially, at the beginning of titles. Day 
describes these words as useless and wasteful. All these are strategies to make titles precise and concise. However, experimental evidence suggests that science authors usually employ grammatical articles in constructing their titles. It was evidenced that not only were applied linguistics, economics and business titles found to contain more usage of definite articles, but also chemistry and computer science titles demonstrated even inclusion of definite and indefinite articles in their titles (Fortanet et al., 1997, 1998). In writing an effective and intelligible title, it is also relevant to exclude abbreviations or jargons as well as numerical values, especially science titles (Bavdakar, 2016; Gustavii, 2008). The assigned reason is that readers may not be familiar with them. Such non-standard expressions and too many technical words can cause confusion and distract concentration in reading research article titles.

Hudson (2016) believes that title construction should be informed by the information content and its attractiveness because effective titles should be able to maximise the impact of a paper. To Moss (2003), writing a title requires two parts: the main subject and the type of study. Both parts of the title will guide readers to make informed choices about the paper (Grant, 2013). This view contradicts Bavdakar (2016) and Day's (1998) claim. However, Day agrees that titles should contain relevant key words that make the titles interesting. The words should be carefully selected in order not to mislead the potential reader. Besides the preceding suggestions on writing research article titles, some findings have been revealed empirically. For instance, Afful's (2017) study of 698 conference paper titles in applied linguistics reported that domain-specific words occurred frequently than research-related, verbal expression and country-related words. Again, Cheng et al. (2012) revealed the occurrence of both domain-specific and non-domain-specific terms. Most of the domain-specific heads were identified to be compound nouns. The current study intended to consider the kind of lexical choices which were used in the three disciplines, focusing on domain-specific and research-based expressions.

So far, the literature suggests that the length of a title remains uncertain despite some empirical reports. It has also been argued that title style identification is based on different parameters. In terms of lexicon selection, domain related words are dominant than research or general terms. Because of uncertainties about title length and other structural issues, the current study made an attempt to conduct a detailed investigation into research article titles, using three disciplines as examples.

\section{CORPUS AND METHODOLOGY}

\section{Research Design}

This study employed the qualitative research approach. The study relied on the purposive sampling technique to select the disciplines to study and the corpus involved, in order to meet the objective of the study. The content analysis approach was used to examine the variables from the data. The results are also descriptive in nature.

\section{Corpus}

The corpus for this study comprised titles of three disciplines (Gynaecology/Obstetrics, Law, and Business). In all, 574 research article titles were extracted from the tables of content of four journals: Obstetric Medicine, Journal of Endometriosis and Pelvic Pain Disorders (representing Gynaecology/ Obstetrics), International Journal of Law, and Business and Society. These journals were selected to represent the three disciplines of Gynaecology/Obstetrics (Gynae/Obst.), Law, and Business. These three disciplines were chosen because the researchers wanted to explore new or less researched areas of investigating research article titles. In order to account for differential structures of titles and considerable number of data for the comparison of titles in the three disciplines, a three-year period was considered in selecting the corpus for the study; thus, the periods between 2016 and 2018, although the publications for 2018 were up to June in each case at the time of collecting the data. The choice of the three years was informed by currency of title writing and also a relative sizable number of the corpus to study. Moreover, these three journals were chosen because of their international prestige.

The analysis of the results and the calculation of percentages were based on individual disciplines. Table 1 presents the number of titles selected from each of the three disciplines with their respective percentages.

It is obvious from Table 1 that Law constituted the highest number of research article (RA) titles, followed by Gynaecology/Obstetric and then Business.

\section{Method of Data Analysis}

The content analysis approach was primarily employed in analysing the features of the titles. Certainly, it was necessary to download some of the articles to verify the sameness of the structures of the titles against those in the table of contents of the journals. So, after the extraction of the titles from the contents of the journals, some of the articles were randomly downloaded. It was confirmed that there were no differences after the comparison. The three different sets of data representing the disciplines were analysed independently so as to arrive at how the features of the titles were presented. The categorisation and the structural analysis of the titles were made manually. Microsoft Word was used in the counting of the words of the titles in order to establish the text length. Manual approach was used for confirming the counting of the words for the text length. In order to account for lexical choices in the construction of the titles, AntConc (version 3.4.3w) was used to generate the word list with ranks and frequencies, which made it easier for seeing the patterns of lexical selections in the titles.

Table 1. Distribution of titles of the three disciplines

\begin{tabular}{lcc}
\hline Discipline & $\begin{array}{c}\text { Number of } \\
\text { Titles (574) }\end{array}$ & Percentage (\%) \\
\hline Gynaecology/Obst & 207 & 36.1 \\
Law & 255 & 44.4 \\
Business & 112 & 19.5 \\
\hline
\end{tabular}




\section{RESULTS AND DISCUSSION}

This section presents the results of the analysis of the corpus, alongside the discussion. The major focus of this work was to analyse the macro-structures and micro-structures of the titles. The results of the data are presented in terms of title length, style and other relevant headings.

\section{Title Length}

Since there is uncertainty about the length of research article titles, this study was motivated to delve into the text length of the titles of the three disciplines. Consequently, this section reports the average text length of the titles in the three disciplines. In this study, the length of a title was conceived simply as the number of words a title had or the 'spaces' it occupied. Just like Moattarian and Alibabaee (2015), the study conceptualised a word as a string of letters or figures with a space preceding it or after it. To consider the number of words in a particular title, the following parameters were followed:

1) Individual words were counted independently. For example, the title Protection of children against sexual abuse (Law - 2018) contains six words.

2) Hyphenated words were counted as a one-word. For instance, the title Fetal anhydramnios following maternal non-steroidal anti-inflammatory drug use in pregnancy (Gynae/Obst - 2018) was counted as a ten-word title.

3) Abbreviations or acronyms which had their referents in the title were counted once. For example, the title Laparoscopic Dissection of the Ureter in Deep-Infiltrating Endometriosis (DIE) of the Pelvis using Ultrasonically Activated Shears (Gynae/Obst - 2017) was counted as a fifteen-word title.

4) Figures or Individual/group of letters with space before or after them and did not have any referent in the title were counted as single words. For example, the title What Have Firms Been Doing? Exploring What KLD Data Report About Firms' Corporate Social Performance in the Period 2000-2010 (Business - 2018) was considered a nineteen-word title.

The length of the titles was measured with the Microsoft Word and manual approaches, which was confirmed by three different researchers besides the authors for verification and certainty. The Microsoft Word was used to double-check the word count. Table 2 presents the results of the total number of words and the average text length of the titles of the disciplines.

We can see from Table 2 that the Business discipline had the highest average number of words, followed by Gynae/ Obst and Law, in relation to title length. The difference between the average text length of Gynaecology/Obst and Law appears relatively close. However, the variations in the average text length of all the disciplines confirm the assertion that genres from different domains are uniquely constructed (Kang \& Yu, 2011). It is mostly argued that, averagely, the sciences usually have longer titles than those in the humanities (e.g., Busch-Lauer, 2000; Haggan, 2004; Fortanet et al., 1997; Nagano, 2015). Business and Law are usually regarded as part of humanities, but the findings of average title length in this study seem to contradict the claims about science titles being longer than those in the humanities, although marginally longer than the titles of Law. In the literature, the average text length of titles was found to range between 6.4 and 13.8 words (e.g., see Afful \& Mwinlaaru, 2010; Haggan, 2004), this study's findings seem to fall within this range. Therefore, any text length of research article titles falling within this range could be regarded as an ideal title length because RA publishing outlets have remained implicit about the suitable text length of titles they require. It must be noted that extremely short titles (between two and three words) might not be able to describe the details of the research to readers, and in the end, not achieving the primary purpose.

Habibzadeh and Yadollahie (2010) believe that authors prefer longer titles because their citation rate is higher than shorter ones. However, Grant (2013) reveals that articles bearing relatively short titles have higher potential to increase their readership and citation frequency than longer ones. This confusion is clarified by the assertion that a good title is the one which is concise, precise and attractive to contain the main ideas in clear terms (Bavdakar, 2016; Grant, 2013). To some extent, longer titles have the potential to increase their informativity content but can, at the same time, lower the generated desire (Bavdakar, 2016; Hudson, 2016). What this means is that, typically, very long titles deter the reader from reading them in full because the reader tends to lose the information focus of the titles or the information the reader absorbs. One of the reasons why the titles are lengthened is due to the use of colons (Fumani et al., 2015). This is because authors mostly resort to the use of colons to elaborate their titles. In the quest to construct each section of the title to carry the stylistic effect and the desired detailed informative content of the title, the author's intention leads to lengthening of the title. Bavdakar (2016) contends that full-sentences can also make titles longer and, due to that, writers often avoid them.

\section{Title Style}

The question about title style in specific or different domains is diversified and it is a matter of style and choice. This study explored the style of titles in the three disciplines investigated. The titles were categorised into two: Single Unit Titles (SUTs) and Compound Unit Titles (CUTs). The Single Unit Titles were classified as those titles which were presented in one unit, whereas the Compound Unit Titles were those titles presented in two segments with or without punctuation marks. Examples are provided in (5) - (7).

5) Substance use in pregnancy: The medical challenge (Gynae/Obst - 2018). CUT.

6) Judicial contribution in enhancing environmental jurisprudence (Law-2018). SUT.

Table 2. Average text length of the three disciplines

\begin{tabular}{lccc}
\hline Word count & Gynaecology/Obst & Law & Business \\
\hline Total words & 2416 & 2853 & 1443 \\
Average & 11.67 & 11.18 & 12.88 \\
words & & & \\
\hline
\end{tabular}


7) The Role of SMEs in Global Production Networks A Swedish SME's Payment of Living Wages at Its Indian Supplier (Business - 2017) CUT.

Examples (5) and (7) were categorised as Compound Unit Titles because they present the titles in two segments with colon and no colon respectively. Such titles are also known as hanging titles (Bavdakar, 2016). Example (6) was classified as a Single Unit Title due to the fact that it presents the title in a single segment. This section, therefore, presents the results of the title style the authors of the research articles employed in the three disciplines. The results are shown in Table 3.

The results from Table 3 shows that the Single Unit Title (SUT) was dominant in two disciplines, indicating that writers' preference for a particular title style is discipline specific. We can see that, in all the disciplines, the Single Unit Title dominated the titles of two disciplines: Gynaecology/Obstetrics and Law, but the Compound Unit Title (CUT) was prevalent in Business. The dominance of Single Unit Titles in this study confirms what is commonly found in the field of medical science (e.g., Cook et al., 2007; Moattarian \& Alibabaee, 2015). Not only does the SUT dominate science titles, but also titles in humanities (e.g., Afful, 2017; Gesuato, 2008; Moattarian \& Alibabaee, 2015). Relative to the occurrence of SUTs in discipline specific, this study disconfirms the fact that science titles employ more SUTs than humanities, owing to the fact that Law recorded relatively higher occurrence of SUTs than Gynaecology/Obstetrics. For instance, Moattarian and Alibabaee (2015) found that Civil Engineering and Dentistry titles exhibited frequent use of SUTs than titles in Applied Linguistics, but the data in the present study has indicated the opposite, especially Law titles.

Surprisingly, the frequency of Compound Unit Titles (CUTs) occurred as high as $71.4 \%$ in Business, which is far higher than the rate of occurrence of the Single Unit Titles in the other two disciplines (see Table 3). This high rate of Compound Unit Titles in Business corroborates the findings of Hartley (2007) and Cheng et al. (2012). According to Cheng et al., the frequent use of compound titles might be due to their dual foci ability, meaning that writers have the option of writing their topic in one segment and specifying the topic in the other segment to contain relevant information for readers. In short, the prevalence of the Single Unit Titles is generally inconsistent in the three disciplines. However, the results of Gynaecology/Obstetrics and Law contradict other studies which claim the domination of Compound Unit Titles (e.g., Cheng et al., 2012; Hartley, 2007).

\section{Syntactic structures of single unit titles}

The syntactic structures of the Single Unit Titles in this study constitute the kind of structural organisations of the titles which were presented in a single segment. The study categorised the structures into phrases, finite and non-finite clauses, declarative or questions. Table 4 presents the frequency of occurrence of these structures in the titles of the three disciplines.

In relation to syntactic structures of the Single Unit Titles across the three disciplines, the results indicate that research article writers' preference for nominal structures in title writing is quite phenomenal, as nominal structures recorded more than $83 \%$ occurrence in each case (see Table 4 ). Although the nominal structure was the most preferred title, the results suggest also that the researchers in Law used the highest rate of the nominal titles, followed by Gynaecology/Obstetrics researchers and then the Business authors (see Table 4). In all, the least used title structures were prepositional phrase and finite clause, which occurred once in each case in Business and Gynae/Obst respectively. Declaratives were also used in all the three disciplines possibly due to the fact that the writers wanted to explicitly make their major findings known to potential readers, as pointed out by Cheng et al. (2012). According to Gustavii (2008), declarative type of title improves readership rather than neutral ones. However, the frequency of declarative titles in all the three disciplines is not common, probably because, in Bavdakar's (2016) view, they appear to be longer. In all the instances, none of the three disciplines employed question structure in constructing the Single Unit Titles. This might be due to the fact that titles in question forms are not mostly preferable because readers will be interested to know the outcome of a paper right from the beginning (Gustavii, 2008). However, it should be noted that titles that show the findings of a paper might not heighten the desire to read the main article because answers are already known.

With regard to discipline specific, the nominal structure constituted $91.5 \%$ of the titles while the other structures (finite clause, non-finite clause and declarative) recorded 8.5\% in Gynae/Obst. The same pattern was encountered in the discipline of Law as the nominal titles occurred as high as $95.2 \%$ whereas non-finite clause and sentence altogether remained less than 5\%. In Business titles, the nominal structure recorded $84.4 \%$ as against $15.6 \%$ for non-finite clause, sentence and prepositional phrase altogether. Although we can see the declarative occurring as the next frequent occurring title with $4.7 \%$ in Gynae/Obst, its occurrence together with the clauses constitutes less than $10 \%$. The findings of extreme prevalence rate of the nominal structure corroborate many claims in the literature (e.g., Afful, 2017; Afful \& Mwinlaaru, 2010; Alcaraz \& Mendez, 2016; Biber \& Gray, 2010; Gesuato, 2008; Moattarian \& Alibabaee, 2015; Wang $\&$ Bai, 2007). However, this result contradicts other studies that other structures (compound structures) are preferred to nominal structures (e.g., Cheng et al., 2012; Hartley, 2007). In accounting for the high rate of nominal titles in research

Table 3. The distribution of title style in the three disciplines

\begin{tabular}{lccc}
\hline Title Style & Gynaecology/Obst & Law & Business \\
\hline Single Unit Title & $106(51.2 \%)$ & $145(56.9 \%)$ & $32(28.6 \%)$ \\
Compound Unit Title & $101(48.8 \%)$ & $110(43.1 \%)$ & $80(71.4 \%)$ \\
\hline
\end{tabular}


articles, some scholars, for instance, Cheng et al. (2012), contend that the nominal structures allow writers the space to condense their information. Writers are able to pack the most relevant information content of the article in the title in a compressed manner because the nominal heads allow pre- and post-modifications coherently. In such situation, the nominal structure is regarded as a reduced strain of clause (Halliday, 1994).

\section{Nominal modifications}

Writers often rely on nominalisation as a linguistic resource which provides an avenue for compressing information that involve a process or clause into the structure of a nominal group, making the nominal titles relevant in academic writing (Eggins, 1994; Halliday, 1998). In view of this, the structures that are often used in containing condensed information in nominal structures were explored in the titles of the three disciplines. Table 5 displays the results of the occurrence of the modifications in the nominal structures.

Generally, all the three disciplines largely employed the complex noun phrase structure to convey the information contents of their respective research article titles. In all the three disciplines, Table 5 suggests that nominal heads which were Both Pre-modified and Post-modified were the most preferred choice, as their frequencies were more than $63 \%$ against the other structures in each situation. This finding is in line with what Fortanet et al. (1997, 1998) found in RA titles in computer science, applied linguistics, business and economics, and chemistry. This tends to suggest that the noun phrases which are information packed can compress information before the subject

Table 4. The distribution of syntactic structures of the SUTs across the disciplines

\begin{tabular}{lccc}
\hline $\begin{array}{l}\text { Syntactic } \\
\text { Structure }\end{array}$ & $\begin{array}{c}\text { Gynaecology/ } \\
\text { Obst }\end{array}$ & Law & Business \\
\hline Nominal & $97(91.5 \%)$ & $138(95.2)$ & $27(84.4)$ \\
Finite Clause & $1(0.9 \%)$ & - & - \\
Non-Finite Clause & $3(2.9 \%)$ & $4(2.8 \%)$ & $1(3.1)$ \\
Declarative & $5(4.7 \%)$ & $3(2.0 \%)$ & $3(9.4)$ \\
Question & - & - & - \\
Prepositional & - & - & $1(3.1)$ \\
Phrase & & & \\
\hline
\end{tabular}

Table 5. Modification distribution of the nominal structures in the disciplines

\begin{tabular}{lccc}
\hline Modification & $\begin{array}{c}\text { Gynaecology/ } \\
\text { Obst }\end{array}$ & Law & Business \\
\hline $\begin{array}{l}\text { Pre-modified } \\
\text { Only }\end{array}$ & - & $12(8.8 \%)$ & $4(14.8 \%)$ \\
$\begin{array}{l}\text { Post-modified } \\
\text { Only }\end{array}$ & $33(34.0 \%)$ & $37(27.0 \%)$ & $3(11.1 \%)$ \\
$\begin{array}{l}\text { Both Pre- \& } \\
\text { Post-modified }\end{array}$ & $62(63.9 \%)$ & $88(64.2 \%)$ & $20(74.1 \%)$ \\
Unmodified & $2(2.1 \%)$ & - & - \\
\hline
\end{tabular}

matter (nominal heads) and after them to limit the focus of information to give vivid account of what the content of an article intends to communicate via the title. However, this result is not in congruence with Moattarian and Alibabaee (2015), because their study revealed that the occurrence of Post-modified Only structures surpassed the other style of modification

Again, the results from this study disconfirm the evidence from other studies that nominal titles which are both pre- and post-modified occur higher in sciences than those in the humanities or soft sciences (e.g., see Fortanet et al., 1997, 1998). The current evidence of this study indicates that the humanities (Law and Business) recorded higher frequency of the complex noun phrase than the science (gynaecology/obstetrics), with Business recording the highest occurrence. Unlike Moattarian and Alibabaee (2015), the results from the current study also indicate that the second frequent modification structure was Post-modified Only structure, with Gynaecology/Obstetrics leading Law and Business. It can also be seen that titles which were Pre-modified Only were recorded in Business and Law, but not in Gynaecology/ Obstetrics. In this case, Business recorded higher occurrence than Law. We can see again from the results that only Gynaecology/Obst recorded two occurrences of structures which were not modified, probably because such structures do not contain enough information for readers.

\section{Post-modification of the NP}

Prepositional phrases (PPs) and relative clauses are the most common post-modifiers of nominal heads (Greenbaum, 1996). Due to this assertion, this section was devoted to ascertain the reality and occurrence of this claim in the construction of research article titles. Table 6 demonstrates the results of the structures usually used as post-modifiers of the nominal heads of the titles of the three disciplines.

Table 6 suggests that the authors of Gynae/Obst., Law, and Business generally employed the Prepositional Phrases and Non-Finite Clauses as their choices in post-modifying their nominal heads in the construction of their titles. This finding partly contradicts Greenbaum's (1996) claim because the Relative Clause is rarely found in the data studied. Table 6 indicates clearly that Prepositional Phrases are authors' most preferred choices in limiting or compressing the lengthy informativity of their titles, which is already an established fact in the literature (Afful \& Mwinlaaru, 2010; Cheng et al., 2012; Moattarian \& Alibabaee, 2015). We can

Table 6. The distribution of post-modifiers of the NP titles of the three disciplines

\begin{tabular}{lccc}
\hline Structure & $\begin{array}{c}\text { Gynaecology/ } \\
\text { Obst }\end{array}$ & Law & Business \\
\hline $\begin{array}{l}\text { Prepositional } \\
\text { Phrase }\end{array}$ & $92(95.8 \%)$ & $122(97.6 \%)$ & $20(90.9 \%)$ \\
$\begin{array}{l}\text { Non-Finite } \\
\text { Clause }\end{array}$ & $4(4.2 \%)$ & $3(2.4 \%)$ & $1(4.55 \%)$ \\
$\begin{array}{l}\text { Relative } \\
\text { Clause }\end{array}$ & - & - & $1(4.55 \%)$ \\
\hline
\end{tabular}


see that the PPs recorded more than $90 \%$ occurrence in each discipline in post-modifying the nominal heads of the titles. Law titles recorded the highest frequency followed by Gynaecology/Obstetrics and Business. It is obvious that only Business recorded the occurrence of all the three post-modifiers (Prepositional Phrase, Non-Finite Clause and Relative Clause), with Relative Clause occurring once (see Table 6).

In relation to the prepositional heads in the prepositional phrase as the commonest structure used in the post-modification of nominal heads, the prevalent prepositions in Gynaecology/Obstetrics were for, of, to, on, during, with, in between and under. The most preferred prepositional phrase head was of which recorded $44.6 \%$, followed by in $(25.0 \%)$. The common prepositions that were used as the PP heads in the post-modification in the titles in Law included of, in, for, under, to, on and by. The heads of the prepositional phrases were dominated by the of preposition, making the of-phrase the widely used phrase in the Law titles. The of-phrase recorded $62.3 \%$ while the others recorded $37.7 \%$. It must be noted that the proposition in happened to be used as the second highest of occurrence, recording 12.3\%. In Business, only six prepositions were used as heads of the PP for post-modifying the heads in the NPs. These included between, amid, of, in, as, and on. The common use of the of-phrase was again observed. The of-phrase recorded the highest occurrence of $65.0 \%$ as against $35.0 \%$ for the other prepositions.

The widespread use of of-phrase to post-modify the nominal heads in title writing is in congruence with what Afful and Mwinlaaru (2010) espouse that it is the commonest prepositional structure used as a postmodifier of nominal heads of titles. The high rate occurrence of prepositional phrases post-modifying the nominal structures is probably not surprising, because such structures used in nominal structures provide a clear focus of the research topic (Biber et al., 1999; Cheng et al., 2012). To Biber et al., PPs serve as devices to link noun phrases with other structures.

\section{Demarcating markers of the compound unit titles}

The Compound Unit Titles (CUTs) were generally conjoined by punctuation marks. It has been revealed that colon, hyphen and comma are the frequently used punctuation marks in title constructions (e.g., Fumani et al., 2015). This study had an interest in investigating the preferred choices of the demarcating markers in presenting the segments of the CUTs. Table 7 reports the results of the kind of punctuation marks used in bringing two foci of the titles together in all the three disciplines.

Table 7 is an indication that the most common punctuation mark for segmenting different parts of the CUTs was colon in all the disciplines. The full stop was not used in any circumstance. Due to the frequent use of colons to demarcate titles, researchers commonly regard such titles as colonic titles (e.g., Hartley, 2007). Hartley reports that titles with colons are extensively employed by academics. Hudson (2016) posits that colonic titles are attractive and distinct. We can see that the discipline of Law employed the highest number of colons in presenting the two segments of the titles, which was followed by Gynaecology/Obstetrics and then Business. This finding is largely in line with a lot of studies that have investigated the syntactic structures of titles (e.g., Alcaraz \& Mendez, 2016; Fumani et al., 2015; Hartley, 2007; Hudson, 2016). It is often asserted that colons can make titles long (e.g., Fumani et al., 2015; Jamali \& Nikzad, 2011). However, it is also suggested that effective titles have the role to motivate readers to the contents of articles and, therefore, should not be long (Jamali \& Nikzad, 2011). The colon offers better opportunity for authors to elaborate their titles to achieve their intention (Fumani et al., 2015; Grant, 2013). The colonic titles are probably desired most because they provide the author the space to balance the focus of the two parts of the title well in respect of the information they convey to readers (Grant, 2013; Hudson, 2016). Because titles are meant to attract large readership, one segment can be made to carry the stylistic details of the title to focus on generating high interest while the other part conveys the details of the title's informativity. In this way, the title will arouse the interest of potential readers to download and read the content of the article (Bavdakar, 2016). It is also probable that authors prefer colons to other punctuation marks as demarcating markers because colons make the segments of titles more attractive to read, thereby, fulfilling the purpose of attracting readers.

It is also important to note that some sub-titles were presented without the use of any punctuation mark, which, surprisingly, became the next highest of occurrence in the Compound Unit Titles, especially in Business with 34 occurrences. Three of such titles were recorded in Law. These titles are often referred to as 'hanging titles' which are used to provide important additional information, just like the use of actual punctuation mark. Examples of such titles are presented in (8) - (10).

8) Corporate Social Responsibility and Job Choice Intentions A Cross-Cultural Analysis (Business and Society)

9) Institutional Resilience in Extreme Operating Environments

The Role of Institutional Work (Business and Society)

10) Doctrinal legal research method a guiding principle in reforming the law and legal system towards the research development (Law)

Table 7. The distribution of punctuation marks in the three disciplines

\begin{tabular}{lccccccc}
\hline Disciplines & $:$ & $;$ & - & $\boldsymbol{P}$ & . & No Mark \\
\hline Gynae/Obst. & 86 & - & 11 & 2 & - & 1 & - \\
Law & 102 & 2 & 2 & 1 & - & - & 3 \\
Business & 36 & - & - & 10 & - & - & 34 \\
Total & 224 & 2 & 13 & 13 & 0 & 1 & 37 \\
\hline
\end{tabular}


In $(8)$ - (10), the sub-titles are in italics. In the examples from Business ( 8 and 9 ), the sub-titles are brought under the main topic/first segment without any punctuation mark; but in example (10), the italic section is a continuation from the first section of the titles. Such sub-titles were often used to describe the main topic, express the method or limit the focus of the topic of the title.

\section{Lexical Choices}

One other essential issue which was considered worth analysing was the prevalent lexical elements used in the three disciplines. The main focus was to look at the choices of words which were common in the writing of titles in each discipline. Twenty-five content words with high frequency were selected for study in each discipline. This means that function words such as prepositions, articles or conjunctions were excluded in order to account for domain specific words or otherwise of the words used in title construction in the three disciplines. This exclusion was reinforced by the fact that lexical words are the semantic core of the main meaning of texts and they are also the main building blocks of texts whereas function words bind the text together (Biber et al., 1999).
Table 8 displays the ranks of 25 words and their respective frequencies in terms of their occurrences in the titles of the three disciplines. Table 8 was generated by AntConc (version $3.4 .3 \mathrm{w}$ ) and modified by removing the grammatical words from it. We can see from Table 8 that the highest frequency of a particular word was recorded in Gynaecology/ Obstetrics (70 occurrences for the first two words), while Law followed with 50 occurrences of the first two words and then Business (with 41 for the first word). These words show how often they were used in the various disciplines in creating the titles.

Table 9 is a display of frequency distribution of content words of the specificity of the words in the titles of the three disciplines. The words were categorised as Domain/Discipline-Specific, Research-Based and Other words. Some examples of Domain/Discipline specific words in Gynaecology/Obstetrics included endometriosis, pregnancy, obstetric or fetal; those of Law included law, legal, rights, judicial or criminal. The words business, firms, organizational, and financial were examples which were tagged as belonging to Business discipline. Generally, words like study, review, report, analysis, research and analysis were contextually categorised as Research-Based in all the three disciplines. General words such as relationship, society, associated, out-

Table 8. Ranks and distributions of content words in the titles of the disciplines

\begin{tabular}{|c|c|c|c|c|c|c|}
\hline \multirow[t]{2}{*}{ Rank } & \multicolumn{2}{|c|}{ Gynaecology/Obst } & \multicolumn{2}{|c|}{ Law } & \multicolumn{2}{|c|}{ Business } \\
\hline & Freq. & Word & Freq. & Word & Freq. & Word \\
\hline 1 & 70 & Endometriosis & 50 & India & 41 & Corporate \\
\hline 2 & 70 & Pregnancy & 50 & Law & 40 & Social \\
\hline 3 & 35 & Case & 34 & Legal & 20 & Business \\
\hline 4 & 26 & Review & 33 & Study & 20 & Responsibility \\
\hline 5 & 22 & Report & 29 & International & 14 & Performance \\
\hline 6 & 19 & Women & 25 & Analysis & 13 & Research \\
\hline 7 & 18 & Study & 25 & Rights & 10 & Society \\
\hline 8 & 16 & Management & 24 & Act & 9 & Analysis \\
\hline 9 & 14 & Disease & 22 & Indian & 9 & Inequality \\
\hline 10 & 14 & Maternal & 21 & Protection & 8 & Governance \\
\hline 11 & 14 & Patients & 19 & Role & 8 & Role \\
\hline 12 & 13 & Outcomes & 18 & Judicial & 7 & Firms \\
\hline 13 & 13 & Pain & 18 & Justice & 7 & Institutional \\
\hline 14 & 12 & Syndrome & 17 & Critical & 7 & Study \\
\hline 15 & 11 & Obstetric & 17 & Human & 6 & Approach \\
\hline 16 & 11 & Treatment & 16 & Right & 6 & Entrepreneurship \\
\hline 17 & 10 & Health & 15 & Women & 6 & Firm \\
\hline 18 & 10 & Patient & 13 & Nigerian & 6 & Organizational \\
\hline 19 & 10 & Pregnant & 12 & Criminal & 5 & Case \\
\hline 20 & 9 & Pelvic & 11 & Special & 5 & Empirical \\
\hline 21 & 8 & Deep & 11 & System & 5 & Financial \\
\hline 22 & 8 & Retrospective & 10 & Civil & 5 & Management \\
\hline 23 & 7 & Adenomyosis & 10 & Corporate & 5 & Relationship \\
\hline 24 & 7 & Associated & 10 & Issues & 5 & Reporting \\
\hline 25 & 7 & Fetal & 10 & Perspective & 5 & Sustainability \\
\hline
\end{tabular}


Table 9. The distribution of lexical choices in the three disciplines

\begin{tabular}{lccc}
\hline Specifications & Gynaecology/Obst & Law & Business \\
\hline Domain-Specific & $18(72.0 \%)$ & $10(40.0 \%)$ & $11(44.0 \%)$ \\
Research-Based & $3(12.0 \%)$ & $2(8.0 \%)$ & $5(20.0 \%)$ \\
Other Words & $4(16.0 \%)$ & $13(52.0 \%)$ & $9(36 \%)$ \\
\hline
\end{tabular}

comes, India, critical and issues were contextually identified as Other words.

In Business and Gynae/Obst, Domain-Specific words dominated the constituents of the titles but Other words were more pervasive in Law (see Table 9). The dominance of Domain-Specific expressions in Gynae/Obst and Business corroborates the claim that Domain-Specific words of RA titles are common and Research-Based words are less frequent (Afful, 2017; Cheng et al., 2012), although in applied linguistics. The occurrence of Research-Based words, especially in the titles of Gynaecology/Obst, defies the suggestions made by most academic writing guides in science (e.g., see Bavdakar, 2016; Day, 1998; Gustavii, 2008). In the Law titles, the high occurrence of Other words might be due to the fact that laws deal with varied disciplines. Possibly, the Domain-Specific words dominated the titles of the two disciplines (Business and Gynae/Obst) because the title is expected to contain enough relevant key words or items that describe the content of the article and, at the same time, facilitate easy search in a database (Fischer \& Zugmond, 2004). Moss (2003) believes that effective and informative titles should contain both domain-specific and research-based words. Grant (2013) contends that titles with the study design provide the reader detailed information to determine the type of project the title reports. It is, therefore, crucial that readers get the two parts of information (Domain-Specific and Research-Based expressions) of a study right from the titles.

\section{CONCLUSION}

This study aimed to investigate the macro and the micro-structures of RA titles from three different disciplines in order to make a significant contribution to title writing scholarship because a title which is poorly written makes an article difficult to be discovered and read (Fox \& Burns, 2015). So far, we can see that the data from the three disciplines have provided some evidence about the expectation of effective titles, based on the fact that the titles studied were accepted and published. The results of the syntactic structures have demonstrated how authors usually construct concise titles which have remained vague in writing guides and other writing materials. We have also seen that variations exist in the textual composition of RA titles. For instance, this study's results revealed that titles in Business (12.88 words) were longer than Gynaecology/Obstetrics (11.67 words) and Law (11.18 words), in terms of average text length. Apart from Business which was extensively dominated by Compound Unit Titles, the titles which were written in single segment were common in Gynaecology/Obstetrics and Law than the Compound Unit Titles. This study also indicated that the nominal structures which were both pre- and post-modified were the most preferred choice for writing titles, but Law recorded the highest followed by Gynaecology/Obstetrics and Business. This implies that to write an affective title requires paying attention to carefully selected words to create a comprehensible title. The extensive use of the nominal structures is a confirmation of what is already in the literature (e.g., Afful, 2017; Biber \& Gray, 2010; Moattarian \& Alibabaee, 2015; Wang \& Bai, 2007). In relation to the modification of the nominal structure, the PP was pervasively used, with the of-phrase being common in all the disciplines.

The study found colon as the predominant punctuation mark in separating the Compound Unit Titles than semi-colon, dash, comma and no mark. Law used more colons than Gynaecology/Obstetrics and Business, drawing attention to the fact that colons are used by authors from different domains but the uses are dissimilar. One remarkable finding about this study was that some of the Compound Unit Titles were segmented without any punctuation marks, which surprisingly became the second highest used style, especially in Business than Law. In terms of lexical selection, Domain-Specific words were prevalent in Gynaecology/Obstetrics and Business than Law, drawing attention to the need to rely on domain specific words in order not to make titles vague. These findings are very significant because researchers in varied domains will find the information in this study useful in writing article titles.

The implications of the findings of this study are significant because both experienced and novel authors will be familiar with the display of how different disciplines construct their titles. Now, the evidence from this study has demonstrated the differences between what is commonly expressed in writing materials and what is practically done. Consequently, authors can rely on the results to make informed choices about the best practices of constructing titles for publications in prestigious journals. Academic writing teaching can also be planned based on the results of this study to improve title construction. A very large data can be studied from the quantitative point of view to confirm the findings of this work.

\section{REFERENCES}

Afful, J. B. A. (2017). A linguistic analysis of conference paper titles in applied linguistics. International Journal of Foreign Language Teaching and Research, 5(18), 11-25.

Afful, J. B. A. \& Mwinlaaru, I. (2010). Commonality and individuality in academic writing: An analysis of conference paper titles of four scholars. ESP Worlds, (1/927), 9, 1-32

Anthony, L. (2001) Characteristic features of research article titles in computer science. IEEE Transactions 
of Professional Communication 44(3): 187-194. DOI: $10.1109 / 47.946464$

Alcaraz, M. A. \& Mendez, D. I. (2016). When astrophysics meets lay and specialised audiences: Titles in popular and scientific paper. Journal of Language and Communication, 3(2), 133-146.

Bavdakar, S. B. (2016). Formulating the right title for a research article. Journal of the Association of Physicians of India, 64, 53-56.

Biber, D. \& Gray, B. (2010). Challenging Stereotypes about Academic Writing: Complexity, Elaboration, Explicitness. Journal of English for Specific Purposes, 9(1), 20, 2-20.

Biber, D., Johansson, S., Leech, G., Conrad, S. \& Finegan, E. (1999). Longman grammar of spoken and written English. England: Longman.

Busch-Lauer, I.A. (2000). Titles of English and German research papers in medicine and linguistics theses and research articles. In A. Trosborg (Ed.) Analysing professional genre (pp. 77-94). Amsterdam/Philadelphia: John Benjamin.

Cheng, S. W., Kuo, C. \& Kuo, C. (2012). Research article titles in applied linguistics. Journal of Academic Language and Learning, 6(1), A1-A14.

Cook, D. A., Beckman, T. J. \& Bordage, G. (2007). A systematic review of titles and abstracts of experimental studies in medical education informative elements missing. Medical Education, 41(11), 1074-1081.

Day, R. A. (1998). How to write and publish a scientific paper. ( $5^{\text {th }}$ ed.). India: The ORYX Press.

Eggins, S. (1994). An introduction to systemic functional linguistics. London \& New York: Continuum.

Fischer, B. A. \& Zigmond, M. J. (2004). Components of a research article. Retrieved from www.survival.pitt.edu

Fortanet G., I., Coll García, J. F., Palmer S. J. C. \& Posteguillo, G. S. (1997). The writing of titles in academic research articles. In R. C. Marín, \& A. R. Navarrete (Eds.) Lenguas aplicadas a las cienciasy la tecnología: Aproximaciones, (pp. 155-158). Cáceres (Spain): Servicio de Publicaciones de la Universidad de Extremadura.

Fortanet, G. I., Posteguillo, G. S., Coll García, J. F. \& Palmer, S. J. C. (1998). Linguistic analysis of research article titles: Disciplinary variations. In I. Vázquez, \& I. Guillén (Eds.) Perspectivas Pragmáticas en Linguistica Aplicada, (pp. 443-447). Zaragoza (Spain): Anubar Ediciones.

Fox, C. W. \& Burns, C. S. (2015). The relationship between manuscript title structure and success: Editorial decisions and citation performance for an ecological journal. Ecology and Evolution, 5(10), 1970-1980.

Fumani, M. R. F. Q., Goltaji, M. \& Parto, P. (2015). The impact of title length and punctuation marks on article citations. Annals of Library and Information Studies, 62(1), 126-132.

Gesuato, S. (2008). Encoding of information in titles: Practices across four genres in Linguistics. In C. Taylor (Ed.). Ecolingua: The role of e-copora in translation and language learning (pp.127-157). Trieste: EUT.
Grant, J. M. (2013). What makes a good title? Health Information and Libraries Journal, 30(4), 259-260.

Greenbaum, S. (1996). English Grammar. Oxford: Oxford University Press.

Gustavii, B. (2008). How to write and illustrate scientific papers. ( $2^{\text {nd }}$ ed.). UK: Cambridge University Press.

Habibzadeh, F. \& Yadollahie, M. (2010). Are shorter articles more attractive for citation? Cross-sectional study of 22 scientific journals. Scientometrics, 51, 165-170. Doi: $10.3325 / \mathrm{cmj} .2010 .51 .165$

Haggan, M. (2004). Research paper titles in literature, linguistics and science: Dimensions of attraction. Journal of Pragmatics, 36(2), 293-317.

Halliday, M. A. K. (1994). An introduction to functional grammar. (2 $2^{\text {nd }}$ ed.). London: Edward Arnold Publishers Limited.

Halliday, M. A. K. (1998). Things and relations: Regrammaticising experience as technical knowledge. In J. R. Martin \& R. Veel (Eds.). Reading science: Critical and functional perspectives on discourse of science (pp. 185235). London: Routledge.

Hartley, J. (2007). Planning that title: Practices and preferences for titles with colons in academic articles. Library \& Information Science Research, 29(4), 553-568.

Hudson, J. (2016). An analysis of the titles of papers submitted to the UK REF in 2014: Authors, disciplines, and stylistic details. Scientometrics 109(1), 871-889. DOI 10.1007/s11192-016-2081-4

Imbelloni, L. E. (2012). Scientific articles' titles: Thanks for the information contained in your title. Revista Brasileira de Anestesiologia, 62(2), 139-140.

Jamali, H. R. \& Nikzad, M. (2011). Article type and its relation with the number of downloads and citations. Scientometrics, 88(2), 653-661. DOI: 10.1007/s11192-0110412-z

Kang, N \& Yu, Q. (2011). Corpus-based stylistic analysis of tourism English. Journal of Language Teaching and Research, 2(1), 129-136.

Moattarian, A. \& Alibabaee, A. (2015). Syntactic structures in research article titles from three different disciplines: Applied linguistics, civil engineering, and dentistry. The Journal of Teaching Language Skills, 7(1), 27-50.

Moss, F. (2003). Titles, abstracts and authors. In G. M. Hall (Ed.), How to write a paper (pp. 42-50). (3 ${ }^{\text {rd }}$ ed.). London: BMJ Publishing group.

Nagano, R. (2015). Research article titles and disciplinary conventions: A corpus study of 8 disciplines. Journal of Academic Writing, 5(1), 133-144.

Rahman, S. \& Hussein, M. (2016). A diachronic study on the information provided by the research titles of applied linguistics journals. Scientometrics, 108(3), $1315-1331$.

Wang, Y. and Y. Bai (2007) A corpus-based syntactic study of medical research article titles. System, 35, 388-399.

Whissell, C. (1999). Linguistic complexity of abstracts and titles in highly cited journals. Perceptual and Motor Skills, 88, 76-86. 